\title{
Corporate Food Paradigms and Health Crisis: The Image of a Syndemic Crash
}

\author{
Hernando Salcedo Fidalgo ${ }^{1}$ \\ Published online: 6 November 2020 \\ (c) Society for International Development 2020
}

\begin{abstract}
The current pandemic is part of the impact of what has been called the 'Anthropocene' or 'Capitalocene'. A holistic narrative, from the perspectives of knowledge construction and new methodologies to address the scenario and the way out of the crisis are necessary. It is with this alternative and a non-reductionist gaze that we intend to present an analysis of the current health crash and the possibilities of structural action on the determinants that have led humanity to the threshold of collapse of the most precious values of modernity.
\end{abstract}

Keywords Resilience $\cdot$ Agency $\cdot$ Economic system $\cdot$ Corporate capture $\cdot$ Food patterns $\cdot$ Food systems

The current convergence of events offers an opportunity to think of the future of the world and the future of the planet. In fact, the health crisis generated by the pandemic zoonosis of SARS Co- $2^{1}$ confronts humanity with the urgent need for transforming our life conceptions and practices in a new social and political direction. On the one hand, the crisis expresses a negative resilience ${ }^{2}$ by the ecosystem's manmade fragility. On the other, it reveals people's exclusion from adequate health services and from the living conditions necessary for being healthy. The recognition of the Noble Peace Price to the World Food Programme (WFP) of the United Nations reflects the fact that the Right to Adequate Food and Nutrition is right at the center of the debate concerning indivisible and essential Human Rights. All of these rights are clearly at risk - the right to health being a visible and symbolic case in point-due to the inequity and the impact of the economic, normative and political organization of the Western world. What we aim to do here is to briefly analyze the structural determinants of the pandemics, from a holistic and non-reductionist perspective.

Hernando Salcedo Fidalgo

investigacion1@ fiancolombia.org

1 Coordinator FIAN Colombia Nutrition's Branch, Bogotá, Colombia

\section{Characterization of a Syndemic}

We are currently witnessing to the convergence of a major social crisis. This is made visible by the co-presence of obesity epidemics, generalized malnutrition and a climate collapse (Swinburn et al. 2019; Willett et al. 2019). The notion of syndemic refers precisely to this point of convergence between the usual determinants of an epidemic and the unconventional determinants that are related to poverty, to the economic system and social inequality, among others. At the intersection of these processes, one biological trajectory is clearly emerging, and that is a response to the biota's equilibrium ${ }^{3}$ via an inverse mode of adaptation that we may want to call 'negative resilience', under the identity of a viral zoonosis (SARS CoV-2) ${ }^{4}$ While we used to think that transmissible diseases were an issue of the past, a pandemia caused yet again by a viral agent has spread uncertainty all over the world and shaken the very pillars

\footnotetext{
${ }^{1}$ Zoonosis is the transmission of diseases, usually infectious, from an animal to the human species, (Morand 2019).

${ }^{2}$ In an article published last year in the Biodiv 50 journal, (Salcedo Fidalgo 2019) we proposed a holistic analysis of the 'food process', in which eco-systemic and nutritional impacts on the prevalence of Chronic Non-Communicable Diseases-CNCD-were defined in terms of negative or inverse resilience, an adaptation process that tends to favor disease and death over the preservation of health and life.

${ }^{3}$ According to authors like Donna Haraway (2015), byota and biosis should be understood as the force of living.

${ }^{4}$ We further develop these concepts in Salcedo Fidalgo (2020).
} 
of western civilization, casting a doubtful light on the credibility of the scientific model.

The link between obesity, chronic non-transmissible diseases (CNTD) and mortality by COVID-19 (SARS CoV-2), is one of the main risk factors for mortality directly related to nutrition. Nutrition, in turn, is directly related to the contemporary food systems. ${ }^{5}$ In other words, the so-called 'modern food systems', generate systemic conditions that end up being responsible for the synchrony of the factors that lead to a zoonosis emergence, understood in its complexity as a syndemic. Simultaneously, the levels of mortality caused by COVID-19 has made visible national health systems' deficiencies, exposing their inability to provide care for the vulnerable populations, as well as showing the inherent fragility of excluded populations' rights. This correlation demonstrates how the dynamics of biology are not only due to the designs of nature, but also to a convergent process of adjusting resilience to the damage that the human species has exerted on nature. Such is the concept of syndemic that we want to introduce and illustrate in this text.

\section{Direct Relationship Between Food Systems and Syndemic Variables: The Unhealthy Corporate Food Paradigm}

The Committee on World Food Security (CFS), through its High-Level Group of Experts, has introduced the notion of 'food systems' since 2017. This category is important, because it has allowed further progress in the perspective of reaching a holistic definition of the food process, but it is still insufficient. Indeed, the reductionism to which systems' theory tends to lead to is not enough if we are to describe and analyze the complexity of food processes. These, indeed, are perhaps much closer to 'network modes' of operation, in which the criteria of unpredictability are stronger. Furthermore, the current food system model is subject to one single idea of economic and social functioning: that imposed by capitalism in its current stage. Due to the globalizing pressure of this economic, political and social order, we can also speak of a 'corporate eating/food pattern'. Although the term was used by authors of the Economy such as Rodríguez Muñoz (2010), today we recover it, broadening its meaning,

\footnotetext{
5 We are referring to the conceptual model from the High Level Panel Experts (HLPE) of the Un Committee on World Food Security (2017), 'understanding that a food system encompasses all the elements (environment, people, inputs, processes, infrastructures, institutions, etc.) and activities related to the production, processing, distribution, preparation and consumption of food, as well as products of these activities, including socio-economic and environmental outcomes'. www.fao.org/fileadmin/user_upload/hlpe/hlpe_documents/ HLPE_Reports/HLPE-Report-12_EN.pdf.
}

to conceptualize food systems, proposing the predominant food pattern imposed by the agro-industry, including the modes of production configured by agro-busines and the consumption modes of ultra-processed edible products. Overwhelming scientific evidence shows that obesity is directly linked to the consumption of highly processed edibles (Monteiro et al. 2017).

Edibles from a high degree of industrial processing, which are the source of pseudo-food consumption-not only in industrialized countries, but increasingly in non-industrialized countries, too- are directly related to the intake of high concentrations of critical nutrients such as glucose, trans fats and sodium, preservatives, colorings, sweeteners and the use of genetically modified organisms. Today it is possible to distinguish edibles from real food based on their degree of processing. It is the corporate-driven dietary pattern that determines malnutrition, in direct relation both to the destruction of biodiversity caused by agribusiness and with the forms of exploitation responsible for the inequity and the marginalization of large sectors of the population deprived of their fundamental human rights (life, health and food). This systemic corporate pattern is at the heart of the causality of the great syndemic we are witnessing today. Companies that produce ultra-processed groceries have launched a global campaign against the conceptualization of the damage to health caused by the high degree of processing of industrial groceries. They argue that this opposition is a banner imposed on the 'freedom of consumption'. They claim the value of autonomy over feeding to hide commercial purpose, such as if food autonomy and its sovereignty were negotiable as a commercial object. This opposition to the defense of the right to adequate food and nutrition is not acceptable from a scientific point of view that is based on research that is free from conflict of interest, and therefore it should be overthrown with the objectivity of this research, based on its data.

\section{The Anthropocene and Capitalocene Approach, and Horizons for Crisis}

In agreement with feminist authors, philosophers and theorists such as Judith Butler, Donna Haraway and Karen Barad, ${ }^{6}$ and with other authors who were at the origin of the conceptualization of the 'anthropocene', we argue that human intervention on nature, its domestication, and the

\footnotetext{
${ }^{6}$ Karen Barad is a pioneer of the concept of 'agential realism'. As members of Faculty in the History of Consciousness Department at the University of California she, together with Santa Cruz and Donna Haraway, have drawn on the philosophy of Judith Butler to take a step towards 'performativity'. The Anthropocene and Capitalocene categories were coined in Haraway et al. (2015).
} 
construction of the idea that the planet is 'at the service' of the human species are the basis of the ideological, social, cultural and economic values that have been imposed as the western societies' dominant paradigm. The very use of a lexicon that refers to 'ecosystem services' reveals and interprets this objectification of nature under the form of 'free' offering of goods that has been incorporated and normalized into the economy of accumulated capital. This perspective is responsible for the destruction of the biota (in the sense of the interrelation of everything that lives on the planet, and not only that which is alive as it refers to hierarchical human interest), and for the planetary transformation we are living in, to an extent that is equivalent to the radical changes of a geological era shift over a short period of time-not even a thousand years, and perhaps only two centuries. We are today at the most critical turning point ever, such that it forces contemporary civilization at the very edge. This is the very same pattern that has blurred and antagonized the perspective of the commons, among which real food, water, air, biodiversity are to be counted. In a nutshell, the common goods of life that provide the basic conditions for health.

\section{A Healthy Conversion, to Avoid Total Collapse}

In the midst of the crisis, we want to make a call, so that the political leaders and the communities that make up the citizens and societies, start to actively deactivate the corporate food system and emancipate themselves from its agroindustrial practices. These are perverse practices of dispossession and hoarding, hazardous forms of monocultures and extensive livestock, including the risky approaches of commercialization through the advertising and marketing of groceries that are not real foods. All these practices are configuring a standardized corporate food process that profoundly damages human health and the health of the planet altogether. A clear nexus that we can now better see. Only if we deactivate this hegemonic pattern, exclusively based on monetary utilitarianism, will we still have a minimal possibility of not crossing the final threshold of the selfdestruction of life on the planet.

The network of interactions that configures the current food process, which others have called the food system, requires radical collective action, which modifies the relationships between the components of the network. If we want to advance towards a human and planetary health, it is necessary to intervene the conventional so-called modern food systems, to generate new networks of interactions around food. This will only be possible if we envision a departure from the prevailing economic and social order. This is what we proposed (Salcedo Fidalgo 2020), in 'six proposals to be implemented immediately': 'Collectively block the advance of so-called modern food systems, by means of a collective political action that demands of states to unquestionably leave behind the corporate food model. This is only possible through peasant, indigenous, family and community agriculture, and agroecology led by women, who have demonstrated their capacity to feed the world'.

- Decentralize the exclusive gaze on the human species and on the economic and social patriarchal model, promoting instead our individual and collective influence towards a 'kinship' that incorporates the forces of all genders, all forms of life, and of biosis.

- Replace the consumption of goods by the generation of inputs that promote biotic strength and positive resilience in all areas—environmental/ecological, social, spiritual, economic and cultural — by means of policies of care as a collective imperative, centered on a social reproduction that builds on the role of women.

- Defend our commons, such as 'real' food, water, space, and biota, to ensure they are exchanged and shared, outside market interests.

- Resort to a form of governance based on equity and polycentric governance that offers adequate food and nutrition to everyone, at any point of the life cycle, recognizing food sovereignty as a goal through coordinated forms of power between diverse centers and spatial levels.

- Reshape an international alliance for biosis, an alliance that prevents the United Nations system from collapsing, before giving way to a new pillar of unity between peoples for planetary life, and where the right to adequate food and nutrition prevails as a guiding axis for the defense of biosis.

\section{References}

Salcedo Fidalgo, Hernando. 2019. Comment sortir du système agroindustriel? Un enjeu de santé publique face à la protection de la biodiversité, Biodiv 50, No. 19, December.

Haraway, Donna. 2015. Anthropocene, capitalocene, plantacionocene, chtulucene: making kin. Environmental Humanities 6: 159-165.

Haraway, Donna, Noboru Ishikawa, Scott F. Gilbert, Kenneth Olwig, Anna L. Tsing, and Nils Bubandt. 2014. Anthropologists are talking - about the anthropocene. Ethnos 81 (3): 535-564.

Monteiro, Carlos Augusto, Geoffrey Cannon, Jean-Claude Moubarac, Renata Bertazzi Levy, Maria Laura C. Louzada, and Patricia Constante Jaime. 2017. The UN decade of nutrition, the NOVA food classification and the trouble with ultra-processing. Public Health Nutrition 21 (1): 5-17.

Morand, Serge. 2019. Biodiversité, élevage et maladies infectieuses. Biodiv' 2050, No. 19, December.

Muñoz, Rodríguez, Flavio Bladimir. 2010. Regímenes, sistema y crisis agroalimentaria, ILSA, El Otro derecho. El sistema agroalimentario: mercantilización, luchas y resistencias. ILSA 42: 45-74. 
Salcedo Fidalgo, Hernando. 2020. The Coronavirus pandemic: a critical reflection on corporate food patterns. Right to Food and Nutrition Watch 12: 16-23.

Swinburn, Boyd A., Vivica I. Kraak, Steven Allender, et al. 2019. The global syndemic of obesity, undernutrition, and climate change: the lancet commission report. The Lancet 393: 791-846.

Willett, Walter, Johan Rockström, Brent Loken, Marco Springmann, Tim Lang, Sonja Vermeulen, et al. 2019. Food in the anthropocene: the EAT-Lancet commission on healthy diets from sustainable food systems. The Lancet 393 (10170): 447-492.

Publisher's Note Springer Nature remains neutral with regard to jurisdictional claims in published maps and institutional affiliations. 